\title{
PRODUÇÃO DE BLENDS A PARTIR DE FRUTOS TROPICAIS E NATIVOS DA AMAZÔNIA ${ }^{1}$
}

\author{
LEANDRO CAMARGO NEVES ${ }^{2}$, RONALDO MORENO BENEDETTE 3 , \\ JÉSSICA MILANEZ TOSIN ${ }^{4}$, EDVAN ALVES CHAGAS ${ }^{5}$, \\ VANUZA XAVIER DA SILVA ${ }^{4}$, MARCOS ANDRÉ DE SOUZA PRILL ${ }^{6}$, \\ SERGIO RUFFO ROBERTO
}

\begin{abstract}
RESUMO-Neste trabalho, objetivou-se o enriquecimento nutricional de néctares de frutos, pelo processamento de blends, usando-se fruteiras tropicais e Amazônicas produzidas em Roraima. Foram utilizados néctares de abacaxi, buriti, caju, camu-camu, carambola, maracujá, murici, lima-ácida Tahiti e taperebá. Foi realizado um ensaio preliminar onde se constatou que os néctares de abacaxi e maracujá seriam utilizados como matrizes e, dos quais, saíram os tratamentos: 2 controles - 100\% de abacaxi e 100\% de maracujá; 1 blend entre as matrizes $-50 \%$ de abacaxi $+50 \%$ de maracujá; 7 blends de cada matriz com cada fruto escolhido, na proporção de 1:1. Foram adicionados benzoato de sódio e dióxido de enxofre, nas concentrações de 500 e 200 ppm, respectivamente, em todos os néctares e blends trabalhados. Os resultados referentes à composição nutricional dos blends refletiram aumento significativo nos valores nutricionais quando em comparação com as matrizes, bem como com os néctares individuais de cada fruto. O mesmo comportamento foi observado mesmo após 10 dias de armazenamento não refrigerado. Com relação à estabilidade microbiológica, apenas os blends que utilizaram o buriti como componente apresentaram comprometimento. As análises químicas dos blends demonstraram padrões distintos das matrizes; entretanto, quando submetidos à análise sensorial, mostraram-se satisfatórias por parte dos julgadores. As composições que mais agradaram os julgadores foram os blends de ambas as matrizes associadas ao camu-camu e murici.
\end{abstract}

Termos para Indexação: Qualidade, sensorial, valor nutritivo, néctar.

\section{PRODUCTION OF BLENDS BASED ON TROPICAL AND NATIVE FRUITS FROM BRAZILIAN AMAZON}

\begin{abstract}
This study was carried out to obtain the nutritional enrichment of nectars of fruits, by means of blends processament, using tropical and Amazonian fruit produced in Roraima. Nectars of pineapple, buriti, cashew, camu-camu, star fruit, passion fruit, murici, Tahiti lime and taperebá were used. A preliminary assay was carried out in which was observed that the nectars of pineapple and passion fruit would be used as matrix, and from these ones the following treatments were originated: 2 controls $-100 \%$ of pineapple and $100 \%$ of passion fruit; 1 blend using the matrix $-50 \%$ of pineapple $+50 \%$ of passion fruit; 7 blends of each matrix with which chosen fruit in the proportion of 1:1. The sodium benzoate and sulfur dioxide were added in the concentrations of 500 and $200 \mathrm{ppm}$, respectively, in all nectars and evaluated blends. The results regarding the nutritional composition of blends reflected a significative raise of nutritional values when compared to the matrix, as well when compared to the individual nectars of each fruit. The same was observed even after 10 days of no refrigerated storage. Regarding the microbiological stability, just the blends in which buriti was used as component were damaged. The chemical analysis of blends showed different standard in relation to the matrix, however, when submitted to the sensorial analysis, showed to be satisfactory by the panel. The compositions that more enjoyed the panel were the blends of both matrixes associated to camu-camu and murici.
\end{abstract}

Index terms: Quality, sensorial, nutricional value, nectar.

\footnotetext{
1(Trabalho 018-10). Recebido em: 05-01-2010. Aceito para publicação em: 13-07-2010.

${ }^{2}$ Prof. Dr. do Depto de Fitotecnia, CCA/UFRR, Km 12 BR 174 s/nº, CEP 69301-970, Boa Vista-RR. E-mail: rapelbtu@hotmail.com ${ }^{3}$ Eng. Agr. e Bolsista EXP-II/CNPq, CCA/UFRR, Km 12 BR 174 s/nº, CEP 69301-970, Boa Vista-RR. E-mail: rmbenedette@hotmail.com ${ }^{4}$ Acadêmica de Agronomia, bolsistas CNPq, CCA/UFRR, Km 12 BR 174 s/nº, CEP 69301-970, Boa Vista-RR. E-mails: vanuzaxs@hotmail.com; jessica.mtosin@hotmail.com

${ }^{5}$ Pesquisador, Embrapa Roraima, Br 177, Km 8, CEP 69301-970. E-mail: echagas@cpafrr.embrapa.br

${ }^{6}$ Eng. Agr. e Bolsista ATP-A/CNPq, CCA/UFRR, Km 12 BR 174 s/nº CEP 69301-970, Boa Vista-RR. E-mail:marcosprill@bol.com.br ${ }^{7}$ Prof. Dr. Depto Agronomia -Centro de Ciências Agrárias/ UEL, C.P. 6001, CEP 86051-990, Londrina-PR. E-mail: sroberto@uel.br
} 


\section{INTRODUÇÃO}

Mesmo com a atual tendência ao consumo de vegetais frescos, verificou-se, nos últimos anos, o crescente aumento na demanda de produtos processados a partir de frutos e hortaliças (BRANCO et al., 2007). A motivação para tal perspectiva deveu-se, sobretudo, pela limitação de tempo e pela praticidade oferecida no consumo de produtos agroindustrializados (MATSUURA; ROLIM, 2002). Visando também ao atendimento dos anseios da população em relação ao valor nutricional desses alimentos (MATSUURA et al., 2004), por exemplo, são utilizados mixes ou blends de sucos ou néctares de frutos, em que características de 2 ou mais espécies são combinadas na elaboração de produtos enriquecidos nutricionalmente (BONOMO et al., 2006). Chamamse mixes ou blends as misturas de sucos ou néctares elaborados com a finalidade de melhorar as características nutricionais e sensoriais dos componentes consumidos isoladamente (MATSUURA; ROLIM, 2002; BRANCO et al., 2007).

A procura por sabores diversificados em sucos ou néctares de frutos também é grande, o que tem levado empresas privadas a desenvolverem novos produtos para atender à demanda já não mais regionalizada. Uma alternativa interessante seria a combinação de diferentes espécies frutícolas como fontes importantes de princípios nutritivos e compostos bioativos naturais (BRANCO et al., 2007). É o caso do blend de suco de caju com extrato de guaraná (SOARES et al., 2001), abacaxi e acerola (MATSUURA; ROLIM, 2002), abacaxi com hortelã (FARIAS et al., 2008) e do tradicional laranja com cenoura (BRANCO et al., 2007).

Os blends apresentam inúmeras vantagens, como a possibilidade de combinação de diferentes aromas e sabores, além da soma de componentes nutricionais, não encontrados em sucos e néctares individuais (QUINTEROS, 1995). Nesse sentido, Matsuura et al. (2004) mencionam que o suco ou néctar de algumas variedades de acerola, apesar de conter elevadas concentrações de vitamina $\mathrm{C}$, apresenta sérias limitações quanto à palatibilidade. Contudo, quando associado a outras espécies, como o abacaxi, nota-se a melhora no sabor do blend, refletido na maior aceitação (MATSUURA; ROLIM, 2002). Assim, outro fator a ser considerado na avaliação da qualidade é a aceitação sensorial do produto, relacionado diretamente com a palatibilidade do blend a ser constituído (MATSUURA; ROLIM, 2002; MATSUURA et al., 2004; BRANCO et al., 2007). Folegatti et al. (2000) mencionaram que a adição de polpa de acerola, até o limite de $34 \%$ na relação do blend formado com mamão, não afetou a aceitação sensorial do produto final, apresentando também aumentos significativos no teor de ácido ascórbico.

Néctares mistos de polpas de mamão e manga foram estudados por Mostafa et al. (1997), havendo a constatação de incrementos nutricionais e da aceitação sensorial em comparação aos produtos quando avaliados individualmente. Da mesma forma, blends produzidos com néctar de goiaba e polpa de mamão também apresentaram pontuação elevada no painel sensorial, devido, principalmente, à consistência e ao sabor, além de notáveis incrementos de vitamina C (TIWARI, 2000). Segundo Matsuura e Rolim, (2002), o suco de abacaxi, contendo em média $20,9 \mathrm{mg}$ de ácido ascórbico. $100 \mathrm{~g}^{-1}$, adicionado de $10 \%$ de suco de acerola, contendo em média $1.000 \mathrm{mg}$ de ácido ascórbico. $100 \mathrm{~g}^{-1}$, resultou num produto com aproximadamente 5 vezes o teor de vitamina $\mathrm{C}$ do suco de abacaxi, sendo que as análises sensoriais não mostraram existir diferenças significativas entre os tratamentos.

Assim, o objetivo deste trabalho foi o incremento nutricional e a manutenção da qualidade dos néctares de maracujá e abacaxi, por meio da adição de néctares de frutos tropicais e nativos da Amazônia, na obtenção de blends com qualidade nutricional, química, sensorial e microbiológica satisfatória.

\section{MATERIAIS E MÉTODOS}

O experimento foi realizado durante a safra de 2008 (janeiro a maio), com frutos colhidos em plena maturidade comercial, nos municípios de Boa Vista-RR, Cantá-RR, Mucajaí-RR, Normandia-RR, São João da Baliza-RR, São Luiz do Anauá-RR e Manaus-AM, distantes $850 \mathrm{~km}$ ao sul e $180 \mathrm{~km}$ ao norte da capital do Estado de Roraima, em cultivos extrativistas (buriti, camu-camu e murici) e pomares produtivos comerciais (caju, abacaxi, carambola, lima-ácida Tahiti, maracujá e taperebá).

Após a colheita de cada fruto, ocorrida entre os meses de janeiro e outubro de 2008, os mesmos foram congelados em nitrogênio líquido e transportados ao LTA/UFRR, sendo então selecionados pela ausência de danos e podridões visuais, e higienizados em solução previamente acidificada $(\mathrm{pH}=3,0)$ de hipoclorito de sódio $(\mathrm{NaOCl})$, a $\left.100 \mathrm{mg} . \mathrm{L}^{-1}\right)$, por 5 minutos. $\mathrm{O}$ armazenamento dos frutos congelados foi realizado a $-80^{\circ} \mathrm{C}$. Na instalação do experimento, os frutos foram novamente selecionados e higienizados em solução previamente acidificada (ácido cítrico, $\mathrm{pH} 3,0)$ de hipoclorito de sódio $(\mathrm{NaOCl})$, a $\left.100 \mathrm{mg} \cdot \mathrm{L}^{-1}\right)$, por 5 minutos, sendo após enxaguados em água destilada e secos em bandejas perfuradas expostas 
ao ar atmosférico $\left(25 \pm 2{ }^{\circ} \mathrm{C}, 70 \pm 3 \%\right.$ de U.R.). Em seguida, foram retiradas cascas e sementes, sendo então as polpas liquidificadas na proporção de 2,5 $\mathrm{mL}$ de polpa para $1 \mathrm{~mL}$ de água destilada. Um volume de $250 \mathrm{~mL}$ de néctar foi acondicionado em sacolas de polietileno de baixa densidade de 0,006 $\mathrm{mm}$ de espessura e capacidade de $500 \mathrm{~mL}$.

Antes da composição final dos tratamentos, foi realizado um ensaio preliminar onde 15 julgadores treinados avaliaram as composições dos possíveis blends, levando em consideração aspectos como a coloração, sabor e aroma objetivando, dessa forma, a viabilidade comercial dos produtos. Constatou-se, a partir daí, que os néctares de abacaxi (G I) e maracujá (G II) poderiam ser utilizados como matrizes e foram elaborados os seguintes tratamentos: 2 controles $100 \%$ de abacaxi (Ananas comosus L.) e 100\% de maracujá (Passiflora edulis f. flavicarpa); 1 blend entre as matrizes (1:1) - abacaxi + maracujá; 7 blends do GI (abacaxi - 1:1) - abacaxi + buriti (Mauritia flexuosa L. F.), abacaxi + caju (Anacardium occidentale L.), abacaxi + camu-camu (Myrciaria dubia H. B. K. (McVough), abacaxi + carambola (Averrhoa carambola L.), abacaxi + lima-ácida Tahiti (Citrus latifolia Tanaka), abacaxi + murici (Byrsonima crassifolia L. Rich.) e abacaxi + taperebá (Spondias mombin L.), 7 blends do G II (maracujá - 1:1) - maracujá + buriti, maracujá + caju, maracujá + camu-camu, maracujá + carambola, maracujá + lima-ácida Tahiti, maracujá + murici e maracujá + taperebá. Baseado na perspectiva de melhor aproveitamento do potencial químico de cada espécie trabalhada, não foi realizada qualquer correção da doçura e/ou acidez dos blends Da mesma forma, em todas as sacolas de polietileno de baixa densidade, devido a ausência no controle térmico (refrigeração), foram adicionados benzoato de sódio (500 ppm) e dióxido de enxofre (200 ppm).

$\mathrm{Na}$ instalação do experimento, foram realizadas análises químicas (sólidos solúveis, acidez titulável e pH) e nutricionais (niacina, cálcio, fósforo, ferro, vitamina B1, B2, e C) dos frutos utilizados no experimento. No processamento dos blends e após 10 dias de armazenamento sem a utilização da refrigeração, avaliaram-se a composição nutricional, a estabilidade microbiológica, os sólidos solúveis (SS), a acidez titulável (AT) e o pH de cada blend, objetivando a verificação de possíveis alterações na composição química e nutricional após a confecção dos néctares. Os teores de sólidos solúveis foram determinados pela leitura refratométrica direta, sendo os resultados expressos em ${ }^{\circ}$ Brix. Os níveis de acidez titulável foram determinados por titulometria de neutralização, com $\mathrm{NaOH}$ a $0,01 \mathrm{~N}$ e ponto de viragem no $\mathrm{pH} 8,2$, sendo os resultados expressos em $\mathrm{g}$ de ácido cítrico.100g de polpa ${ }^{-1}$. O pH foi determinado por potenciometria em amostra triturada e homogeneizada. O teor de ácido ascórbico (mg por $100 \mathrm{~g}$ de polpa) foi determinado segundo método de Carvalho et al. (1990). As análises de Coliformes a 35 e $45^{\circ} \mathrm{C}$, Salmonella, fungos e leveduras e de bactérias lácticas foram realizadas segundo metodologia proposta por American Public Health Association (2001), obedecendo, inclusive, à Resolução RCD n ${ }^{\circ} 12$, de 2 de janeiro de 2001, da Agência Nacional de Vigilância Sanitária (ANVISA). Para as análises nutricionais, foram determinadas as vitaminas B1 e B2, extraídas segundo AOAC (2000), e quantificadas por CLAE com detector de fluorescência, segundo Van de Weerdhof et al. (1973); a niacina foi determinada por extração segundo AOAC (2000) e quantificada por cromatografia líquida de alta eficiência (CLAE), utilizando detector de arranjo de diodos, de acordo com Lam et al. (1984); os minerais cálcio, ferro e fósforo foram determinados por espectrometria de emissão atômica com fonte de plasma indutivamente acoplado - ICP-OES, segundo AOAC (2000), com mineralização por via seca ou úmida, de acordo com a amostra. Os resultados foram expressos em mg.100 $\mathrm{g}$ de $\mathrm{polpa}^{-1}$. Ao final do experimento, realizou-se o teste de preferência, utilizando-se de 115 julgadores não treinados em 2 supermercados locais, pela escala hedônica de 5 pontos (MORAES, 1988) - gostei muitíssimo (nota 5); gostei muito (nota 4); gostei (nota 3); desgostei muito (nota 2) e desgostei muitíssimo (nota 1).

O delineamento experimental empregado no experimento foi o inteiramente casualizado, com esquema fatorial $17 \times 2$ (tratamentos e épocas de análise), com 3 repetições e 10 unidades amostrais por repetição. Os dados foram submetidos à análise de variância, pelo teste $\mathrm{F}$, e a comparação de médias, efetuada pelo teste de Tukey, a $5 \%$ de probabilidade.

\section{RESULTADOS E DISCUSSÃO}

Quanto à análise de contaminantes microbiológicos, a contagem de coliformes a 35 e $45^{\circ} \mathrm{C}$ e Salmonella, em todos os tratamentos testados, encontrava-se dentro dos padrões microbiológicos estabelecidos pela ANVISA (2001). Nesse sentido, não foram detectadas a presença de Salmonella em $25 \mathrm{~g}$ de amostra e mais do que $10^{2} \mathrm{NMP}$ de coliformes a $45^{\circ} \mathrm{C} . \mathrm{g}^{-1}$ de amostra, além de valores inferiores a 3 NMP de coliformes a $35^{\circ} \mathrm{C} . \mathrm{g}^{-1}$ de amostra (Tabela 1). De acordo com Bonnas et al. (2003), a presença ou ausência de coliformes pode funcionar como parâmetro de qualidade das condições higiênicosanitárias no processamento de alimentos. 
O tratamento com o hipoclorito de sódio antes do processamento dos néctares, a exemplo do que ocorreu no experimento de Neves et al. (2006) e Costa et al. (2003), não foi suficiente para o controle de fungos e leveduras, e de bactérias lácticas em alguns blends, mesmo com a utilização dos agentes químicos preservativos. Nesse sentido, nos tratamentos em que as matrizes foram misturadas ao néctar de buriti, foram observados elevados níveis de contaminação por fungos e leveduras, e por bactérias lácticas, sendo significativamente maiores que nos demais tratamentos. Esse comportamento deveuse, possivelmente, à baixa acidez e ao elevado $\mathrm{pH}$ desses blends, detectados tanto no início do experimento quanto após 10 dias de armazenamento em condições não controladas de temperatura (Tabela 3). Considerou-se, também, que as condições de processamento e acondicionamento foram adequadas, $\mathrm{o}$ que se pressupõe que, pelas razões descritas acima, a ação do agente sanitizante, bem como dos preservativos adicionados ( $>$ eficiência em meio ácido), não foram suficientes para diminuir a flora microbiana presente nos frutos. Desse modo, segundo o estudo de Mattiuz et al. (2004), reafirma-se a hipótese de que a acidez pronunciada seja benéfica sob o ponto de vista microbiológico, pois inibe o crescimento microbiano de tal maneira que não compromete a qualidade sensorial e química dos alimentos.

Nos blends sem a adição do néctar de buriti, onde a ação antimicrobiana do benzoato de sódio e dióxido de enxofre foi considerada positiva, a acidez do meio, bem como o próprio $\mathrm{pH}$ levemente ácido, garantiu a eficácia do tratamento antimicrobiano já esperado dos preservativos químicos.

No que diz respeito à caracterização química dos néctares, todos, sem exceção, apresentaram teores e níveis de SS, AT e pH (Tabela 2) dentro dos padrões de identidade e qualidade estabelecidos pelo Brasil (2003). Esses dados permitiram o entendimento de que a colheita dos frutos levou em consideração o completo desenvolvimento fisiológico e, supostamente, a adequada maturação comercial de cada fruto, principalmente para os frutos não climatéricos, como é o caso do abacaxi, da carambola e da lima-ácida Tahiti. Nesse contexto, Silva et al. (2005) ressaltam a importância qualitativa da correta determinação do ponto e a qualidade final das polpas e sucos de frutos, pois, se colhidos antes do ideal, nunca apresentariam características sensoriais de sabor e aroma satisfatórios.

Após a constituição dos blends, foi perceptível a modificação dos parâmetros $\mathrm{SS}$, AT e pH (Tabela 3), em comparação a cada um dos néctares analisados no início do experimento (Tabela 2).
Vale ressaltar, em comparação com os resultados dos ensaios preliminares, que as matrizes maracujá e abacaxi, as quais apresentaram, significativamente, os maiores teores de SS, também mantiveram e/ou melhoraram o aspecto sensorial de cada blend formado (Figura 1). Dessa forma, logo após a constituição dos tratamentos, os blends que apresentavam na composição o camu-camu e o murici, que quando néctares apresentavam os menores teores de SS (média 4,40 ${ }^{\circ}$ Brix), apresentaram incrementos significativos nos teores de SS, atingindo médias na ordem de $8,40^{\circ}$ Brix (Tabela 3). Como resultado tecnológico dessa elevação, ao final do experimento, os blends elaborados por ambas as matrizes, em associação ao camu-camu e ao murici, foram os preferidos no teste de preferência, melhorando, inclusive, a preferência por ambos como blends em detrimento aos néctares individuais (Figura 1). Em conformidade com esses resultados, o relato de Matsuura et al. (2004) menciona que o suco ou néctar de algumas variedades de acerola, apesar de conter elevadas concentrações de vitamina $\mathrm{C}$, apresentam limitações quanto à palatibilidade. Contudo, quando associado a outras espécies, como o abacaxi, pode-se notar a melhora no sabor do blend, refletido na maior aceitação por parte dos julgadores (MATSUURA; ROLIM, 2002).

Assim, ao analisar a composição química dos melhores blends no teste de preferência, após 10 dias de armazenamento (as 2 matrizes + camu-camu/murici), observaram-se teores de SS e AT intermediários, ou seja, os julgadores preferiram blends com doçura e acidez característica, porém não pronunciados, o que pode ter descartado os blends com elevados teores de SS e reduzidos teores de AT. Contudo, deve-se também levar em consideração fatores como a oxidação e o amargor, visto que os blends de abacaxi + lima-ácida Tahiti e maracujá + lima-ácida Tahiti, mesmo possuindo valores semelhantes de SS e AT dos blends preferidos no painel sensorial, ainda assim não apresentaram resultados satisfatórios. Segundo Quinteros (1995), isso pode ser explicado pelo fato de que os blends, por apresentarem a combinação de diferentes aromas e sabores, além da soma de componentes químicos e nutricionais, a escolha do consumidor é conduzida pelo somatório desses fatores em detrimento à análise desses mesmos componentes de maneira isolada.

No entendimento da composição química dos blends, à exceção daqueles contendo buriti, que apresentavam os menores teores de AT e os maiores níveis de $\mathrm{pH}$, além da elevada atividade microbiana (Tabela 1), os demais blends apresentaram resultados intermediários nos teores e níveis de SS, AT e pH, em consideração ao néctar individual. Comportamento 
semelhante foi observado nesses blends, também após os 10 dias de armazenamento, sem o controle da temperatura. Contudo, como já mencionado, à exceção dos blends formados com o camu-camu e o murici, os teores de SS foram significativamente menores aos 10 dias de armazenamento não refrigerado, em comparação ao início do experimento. $\mathrm{Na}$ análise dos teores de AT, em todos os tratamentos testados, verificaram-se decréscimos significativos da acidez orgânica em relação ao tempo. Quanto ao $\mathrm{pH}$, à exceção dos tratamentos em que se utilizou o néctar de buriti, os níveis nos demais blends foram estatisticamente iguais ao início do experimento. Assim, é possível considerar que, nos blends elaborados com abacaxi/maracujá + buriti, os incrementos significativos nos níveis de $\mathrm{pH}$, como reflexo da elevada atividade microbiana de fungos, leveduras e bactérias lácticas, tenham diminuído a eficiência da ação dos preservativos utilizados, que possuem melhor atividade em $\mathrm{pH}$ abaixo de 4,0.

Quanto às análises dos componentes vitamínicos e minerais nos blends, do mesmo modo que ocorreu na composição química, notou-se o padrão intermediário entre os valores obtidos em cada néctar, de cada componente vitamínico, quando analisados na forma de blend. Dessa maneira, de acordo a Tabela 4 , os néctares que possuíam quantidades superiores de niacina (todos, à exceção ao buriti), vitamina B1 (sem diferença significativa), vitamina B2 (maracujá e buriti) e vitamina C (camu-camu), bem como, dos minerais cálcio (buriti e murici), fósforo (buriti) e ferro (buriti e carambola), puderam enriquecer, nutricionalmente, os demais néctares, assim como já haviam descrito Branco et al.(2007), Bonomo et al. (2006) e Matsuura e Rolim (2002). A partir daí, formaram-se blends com características químicas mais bem equilibradas do que quando néctares individuais. Contudo, como observado nas Tabelas 4; 5 e 6 , os resultados variaram de acordo com a composição vitamínica em cada espécie. Dessa forma, ao interpretar de maneira globalizada as características microbiológicas, químicas e do painel sensorial no néctar e nos blends contendo buriti, nos quais foram observados os maiores conteúdos de cálcio, fósforo, ferro e das vitaminas B1 e B2, verificouse que esses blends não apresentavam padrões de qualidade satisfatório, principalmente do ponto de vista microbiológico. Outro fator importante diz respeito às análises vitamínicas e de minerais, nesses mesmos tratamentos, aos 10 dias de armazenamento sem refrigeração, onde foram constatadas as maiores perdas vitamínicas em porcentagem, visto que não foram detectadas perdas visíveis nos conteúdos de minerais.

Como um dos principais reguladores na qualidade química e na estabilidade microbiológica e oxidativa dos néctares e blends, conforme descrito por Neves (2009), o conteúdo de vitamina $\mathrm{C}$ foi marcante no néctar e nos blends compostos pelo camucamu, tanto no início dos tratamentos quanto ao final dos 10 dias de armazenamento em condições não controladas de temperatura. Aspecto semelhante foi relatado por Matsuura e Rolim (2002) onde o blend formado a partir da acerola, dado o elevado conteúdo de vitamina $C$, aumentou em até 12 vezes o conteúdo dessa mesma vitamina quando comparado ao suco integral e pasteurizado de abacaxi. Nesse sentido, justamente pela notável característica antioxidante da vitamina $\mathrm{C}$, presume-se que esse incremento nutricional tenha colaborado na melhor preservação da qualidade dos blends elaborados com o camu-camu. 
TABELA 1- Coliformes a $35^{\circ} \mathrm{C}$ (I) e $45^{\circ} \mathrm{C}$ (II) Salmonella (III), Contagem de fungos e leveduras (IV) e de bactérias lácticas (V), em $100 \mathrm{~mL}$ de néctares e blends de frutos tropicais e Amazônicos, armazenados por 10 dias sem refrigeração, sob a adição de benzoato de sódio e dióxido de enxofre. Boa Vista-RR .

\begin{tabular}{|c|c|c|c|c|c|c|c|}
\hline \multirow{2}{*}{\multicolumn{2}{|c|}{ Proporções/Grupos }} & \multirow[t]{2}{*}{ Tratamentos } & \multicolumn{5}{|c|}{ Análises microbiológicas } \\
\hline & & & $I^{*}$ & II* & III** & $I V * * *$ & $\mathbf{V} * * *$ \\
\hline $100 \%$ & & abacaxi & $<3$ & - & - & $1,03 \times 10^{-4} \mathrm{~B}$ & $1,13 \times 10^{-2} \mathrm{~B}$ \\
\hline $100 \%$ & & maracujá & $<3$ & - & - & $2,12 \times 10^{-4} \mathrm{~B}$ & $3,44 \times 10^{-2} \mathrm{~B}$ \\
\hline blends & $1: 1$ & maracujá + abacaxi & $<3$ & - & - & $3,87 \times 10^{-4} \mathrm{~B}$ & $2,70 \times 10^{-1} \mathrm{~B}$ \\
\hline \multirow{7}{*}{ GI } & $1: 1$ & abacaxi + buriti & $<3$ & - & - & $7,23 \times 10^{1} \mathrm{~A}$ & $4,11 \times 10^{5} \mathrm{~A}$ \\
\hline & $1: 1$ & abacaxi + caju & $<3$ & - & - & $2,21 \times 10^{-4} \mathrm{~B}$ & $3,20 \times 10^{-2} \mathrm{~B}$ \\
\hline & $1: 1$ & abacaxi + camu-camu & $<3$ & - & - & $1,99 \times 10^{-4} \mathrm{~B}$ & $1,49 \times 10^{-2} \mathrm{~B}$ \\
\hline & $1: 1$ & abacaxi + carambola & $<3$ & - & - & $2,34 \times 10^{-4} \mathrm{~B}$ & $2,90 \times 10^{-2} \mathrm{~B}$ \\
\hline & $1: 1$ & abac. + lima-ácida Tahiti & $<3$ & - & - & $1,77 \times 10^{-4} \mathrm{~B}$ & $1,18 \times 10^{-2} \mathrm{~B}$ \\
\hline & $1: 1$ & abacaxi + murici & $<3$ & - & - & $3,02 \times 10^{-4} \mathrm{~B}$ & $1,03 \times 10^{-2} \mathrm{~B}$ \\
\hline & $1: 1$ & abacaxi + taperebá & $<3$ & - & - & $3,10 \times 10^{-4} \mathrm{~B}$ & $3,28 \times 10^{-2} \mathrm{~B}$ \\
\hline \multirow{7}{*}{ GII } & $1: 1$ & maracujá + buriti & $<3$ & - & - & $3,77 \times 10^{1} \mathrm{~A}$ & $7,33 \times 10^{4} \mathrm{~A}$ \\
\hline & 1:1 & maracujá + caju & $<3$ & - & - & $2,29 \times 10^{-4} \mathrm{~B}$ & $2,30 \times 10^{-2} \mathrm{~B}$ \\
\hline & $1: 1$ & maracujá + camu-camu & $<3$ & - & - & $2,11 \times 10^{-4} \mathrm{~B}$ & $3,02 \times 10^{-2} \mathrm{~B}$ \\
\hline & $1: 1$ & maracujá + carambola & $<3$ & - & - & $2,36 \times 10^{-4} \mathrm{~B}$ & $2,10 \times 10^{-2} \mathrm{~B}$ \\
\hline & $1: 1$ & marac. + lima-ácida Tahiti & $<3$ & - & - & $2,18 \times 10^{-4} \mathrm{~B}$ & $1,89 \times 10^{-2} \mathrm{~B}$ \\
\hline & $1: 1$ & maracujá + murici & $<3$ & - & - & $3,01 \times 10^{-4} \mathrm{~B}$ & $1,45 \times 10^{-2} \mathrm{~B}$ \\
\hline & 1:1 & maracujá + taperebá & $<3$ & - & - & $2,72 \times 10^{-4} \mathrm{~B}$ & $1,74 \times 10^{-2} \mathrm{~B}$ \\
\hline
\end{tabular}

*Número mais provável por grama de amostra $\left(\mathrm{NMP} . \mathrm{g}^{-1}\right)$. **Presença em mais de $25 \mathrm{~g}$ de amostra ***Unidades formadoras de colônia por grama de amostra (UFC. $\left.\mathrm{g}^{-1}\right)$.

As médias seguidas das mesmas letras, nas colunas (tratamentos), não diferem entre si, ao nível de 5\% de probabilidade, pelo teste de Tukey.

TABELA 2 - Composição nutricional média (em g.100 mL $\mathrm{mL}^{-1}$ ) e composição química média (em 100mL) dos néctares de frutos tropicais e Amazônicos, no início do experimento (dia 0), sob a adição de benzoato de sódio e dióxido de enxofre. Boa Vista-RR.

\begin{tabular}{cccccccc|ccc}
\hline Frutos & \multicolumn{7}{c|}{ Composição Nutricional } & \multicolumn{3}{c}{ Composição Química } \\
\hline & Niacina & Cálcio & Fósforo & Ferro & Vit. B1 & Vit. B2 & Vit. C & AT & SS & pH \\
\hline abacaxi & $0,23 \mathrm{~A}$ & $17,50 \mathrm{~B}$ & $8,20 \mathrm{~B}$ & $0,53 \mathrm{~B}$ & $0,06 \mathrm{~A}$ & $0,03 \mathrm{~B}$ & $32,50 \mathrm{~B}$ & $1,02 \mathrm{~B}$ & $13,8 \mathrm{~A}$ & $3,8 \mathrm{~B}$ \\
buriti & $0,007 \mathrm{C}$ & $150,5 \mathrm{~A}$ & $42,3 \mathrm{~A}$ & $5,32 \mathrm{~A}$ & $0,04 \mathrm{~A}$ & $0,28 \mathrm{~A}$ & $0,02 \mathrm{~B}$ & $0,35 \mathrm{D}$ & $10,8 \mathrm{~B}$ & $5,2 \mathrm{~A}$ \\
caju & $0,44 \mathrm{~A}$ & $4,30 \mathrm{~B}$ & $19,20 \mathrm{~B}$ & $1,18 \mathrm{AB}$ & $0,03 \mathrm{~A}$ & $0,02 \mathrm{~B}$ & $192,5 \mathrm{~B}$ & $0,81 \mathrm{BC}$ & $12,1 \mathrm{~A}$ & $3,8 \mathrm{~B}$ \\
camu-camu & $0,06 \mathrm{AB}$ & $28,40 \mathrm{~B}$ & $15,56 \mathrm{~B}$ & $0,78 \mathrm{~B}$ & $0,02 \mathrm{~A}$ & $0,03 \mathrm{~B}$ & $2180 \mathrm{~A}$ & $4,51 \mathrm{~A}$ & $6,6 \mathrm{C}$ & $2,7 \mathrm{~B}$ \\
carambola & $0,32 \mathrm{~A}$ & $31,00 \mathrm{~B}$ & $12,10 \mathrm{~B}$ & $3,30 \mathrm{~A}$ & $0,05 \mathrm{~A}$ & $0,02 \mathrm{~B}$ & $21,1 \mathrm{~B}$ & $0,68 \mathrm{C}$ & $6,8 \mathrm{C}$ & $3,5 \mathrm{~B}$ \\
lima-ácida Tahiti & $0,20 \mathrm{~A}$ & $31,80 \mathrm{~B}$ & $17,50 \mathrm{~B}$ & $0,81 \mathrm{~B}$ & $0,02 \mathrm{~A}$ & $0,02 \mathrm{~B}$ & $34,3 \mathrm{~B}$ & $5,5 \mathrm{~A}$ & $8,7 \mathrm{~B}$ & $2,8 \mathrm{~B}$ \\
maracujá & $1,60 \mathrm{~A}$ & $12,45 \mathrm{~B}$ & $17,20 \mathrm{~B}$ & $1,85 \mathrm{AB}$ & $0,03 \mathrm{~A}$ & $0,15 \mathrm{~A}$ & $33,15 \mathrm{~B}$ & $2,90 \mathrm{AB}$ & $13,8 \mathrm{~A}$ & $3,0 \mathrm{~B}$ \\
murici & $0,52 \mathrm{~A}$ & $88,00 \mathrm{~A}$ & $22,10 \mathrm{AB}$ & $1,53 \mathrm{AB}$ & $0,02 \mathrm{~A}$ & $0,05 \mathrm{~B}$ & $29,20 \mathrm{~B}$ & $0,80 \mathrm{BC}$ & $4,2 \mathrm{C}$ & $3,8 \mathrm{~B}$ \\
taperebá & $0,45 \mathrm{~A}$ & $27,50 \mathrm{~B}$ & $30,20 \mathrm{AB}$ & $2,80 \mathrm{AB}$ & $0,08 \mathrm{~A}$ & $0,05 \mathrm{~B}$ & $22,50 \mathrm{~B}$ & $1,64 \mathrm{~B}$ & $8,8 \mathrm{~B}$ & $3,0 \mathrm{~B}$ \\
\hline
\end{tabular}

As médias seguidas das mesmas letras, nas colunas (tratamentos), não diferem entre si, ao nível de 5\% de probabilidade, pelo teste de Tukey. 
TABELA 3- Sólidos solúveis (SS), acidez titulável (AT) e pH em $100 \mathrm{~mL}$ dos néctares e blends de frutos tropicais e Amazônicos, no início do experimento (dia 0) e após armazenamento por 10 dias sem refrigeração, sob a adição de benzoato de sódio e dióxido de enxofre. Boa Vista-RR.

\begin{tabular}{|c|c|c|c|c|c|c|c|c|}
\hline \multicolumn{3}{|c|}{ Proporções/Grupos } & \multicolumn{6}{|c|}{ Composição química } \\
\hline & & & \multicolumn{3}{|c|}{ Dia 0} & \multicolumn{3}{|c|}{ Dia 10} \\
\hline & & & SS & AT & pH & SS & AT & pH \\
\hline \multicolumn{2}{|c|}{$100 \%$} & abacaxi & $13,8 \mathrm{Aa}$ & $1,02 \mathrm{Ba}$ & $3,8 \mathrm{Ba}$ & $13,1 \mathrm{Ab}$ & $0,84 \mathrm{Cb}$ & $3,8 \mathrm{Ba}$ \\
\hline \multicolumn{2}{|c|}{$100 \%$} & maracujá & $13,8 \mathrm{Aa}$ & $2,90 \mathrm{Aa}$ & $3,0 \mathrm{Ca}$ & $13,3 \mathrm{Ab}$ & $1,95 \mathrm{ABb}$ & $2,9 \mathrm{Ba}$ \\
\hline blends & $1: 1$ & maracujá + abacaxi & $13,5 \mathrm{Aa}$ & $2,02 \mathrm{ABa}$ & $3,2 \mathrm{Ca}$ & $13,0 \mathrm{Ab}$ & $1,23 \mathrm{BCb}$ & $3,1 \mathrm{Ba}$ \\
\hline \multirow{7}{*}{ GI } & 1:1 & abacaxi + buriti & $11,8 \mathrm{Ba}$ & $0,56 \mathrm{Ca}$ & $4,4 \mathrm{Ab}$ & $9,2 \mathrm{Bb}$ & $0,15 \mathrm{Db}$ & $5,4 \mathrm{Aa}$ \\
\hline & 1:1 & abacaxi + caju & $12,8 \mathrm{Aa}$ & $0,91 \mathrm{Ba}$ & $3,6 \mathrm{Ba}$ & $10,2 \mathrm{Bb}$ & $0,75 \mathrm{Cb}$ & $3,4 \mathrm{Ba}$ \\
\hline & 1:1 & abacaxi + camu-camu & $8,9 \mathrm{Ca}$ & $3,12 \mathrm{Aa}$ & $3,1 \mathrm{Ca}$ & $8,0 \mathrm{Ba}$ & $2,23 \mathrm{Ab}$ & $2,9 \mathrm{Ca}$ \\
\hline & 1:1 & abacaxi + carambola & $9,3 \mathrm{Ca}$ & $0,82 \mathrm{Ba}$ & $3,6 \mathrm{Ba}$ & $7,7 \mathrm{BCb}$ & $0,45 \mathrm{Cb}$ & $3,6 \mathrm{Ba}$ \\
\hline & 1:1 & abac. + lima-ácida Tahiti & $9,8 \mathrm{Ca}$ & $3,89 \mathrm{Aa}$ & $3,3 \mathrm{BCa}$ & $9,0 \mathrm{Bb}$ & $2,70 \mathrm{Ab}$ & $3,5 \mathrm{Ba}$ \\
\hline & 1:1 & abacaxi + murici & $7,7 \mathrm{Ca}$ & $0,92 \mathrm{Ba}$ & $3,7 \mathrm{Ba}$ & $6,5 \mathrm{Ca}$ & $0,54 \mathrm{Cb}$ & $3,5 \mathrm{Ba}$ \\
\hline & 1:1 & abacaxi + taperebá & $10,1 \mathrm{Ba}$ & $1,33 \mathrm{Ba}$ & $3,5 \mathrm{BCa}$ & $8,8 \mathrm{Bb}$ & $0,78 \mathrm{Cb}$ & $3,8 \mathrm{Ba}$ \\
\hline \multirow{7}{*}{ GII } & 1:1 & maracujá + buriti & $11,4 \mathrm{Ba}$ & $0,66 \mathrm{Ca}$ & $3,9 \mathrm{Ab}$ & $8,8 \mathrm{Bb}$ & $0,20 \mathrm{Db}$ & $5,1 \mathrm{Aa}$ \\
\hline & 1:1 & maracujá + caju & $12,5 \mathrm{Aa}$ & $1,38 \mathrm{Ba}$ & $3,5 \mathrm{BCa}$ & $10,2 \mathrm{Bb}$ & $0,78 \mathrm{Cb}$ & $3,3 \mathrm{Ba}$ \\
\hline & 1:1 & maracujá + camu-camu & $9,0 \mathrm{Ca}$ & $4,02 \mathrm{Aa}$ & $2,9 \mathrm{Ca}$ & $8,2 \mathrm{BCa}$ & $3,21 \mathrm{Ab}$ & $3,0 \mathrm{Ba}$ \\
\hline & 1:1 & maracujá + carambola & $9,1 \mathrm{Ca}$ & $1,89 \mathrm{Ba}$ & $3,3 \mathrm{Ca}$ & $7,9 \mathrm{BCb}$ & $1,23 \mathrm{BCb}$ & $3,4 \mathrm{Ba}$ \\
\hline & 1:1 & marac. + lima-ácida Tahiti & $9,5 \mathrm{Ca}$ & $4,16 \mathrm{Aa}$ & $3,0 \mathrm{Ca}$ & $8,5 \mathrm{Bb}$ & $2,87 \mathrm{Ab}$ & $3,0 \mathrm{Ba}$ \\
\hline & 1:1 & maracujá + murici & $8,0 \mathrm{Ca}$ & $1,88 \mathrm{Ba}$ & $3,3 \mathrm{Ca}$ & $7,7 \mathrm{Ca}$ & $1,22 \mathrm{BCb}$ & $3,3 \mathrm{Ba}$ \\
\hline & 1:1 & maracujá + taperebá & $9,6 \mathrm{Ca}$ & $2,20 \mathrm{ABa}$ & $3,1 \mathrm{Ca}$ & $9,0 \mathrm{Bb}$ & $1,67 \mathrm{Bb}$ & $3,0 \mathrm{Ba}$ \\
\hline
\end{tabular}

As médias seguidas das mesmas letras, nas colunas (tratamentos - maiuscúla) e nas linhas (tempo - minúscula), não diferem entre si, ao nível de $5 \%$ de probabilidade, pelo teste de Tukey.
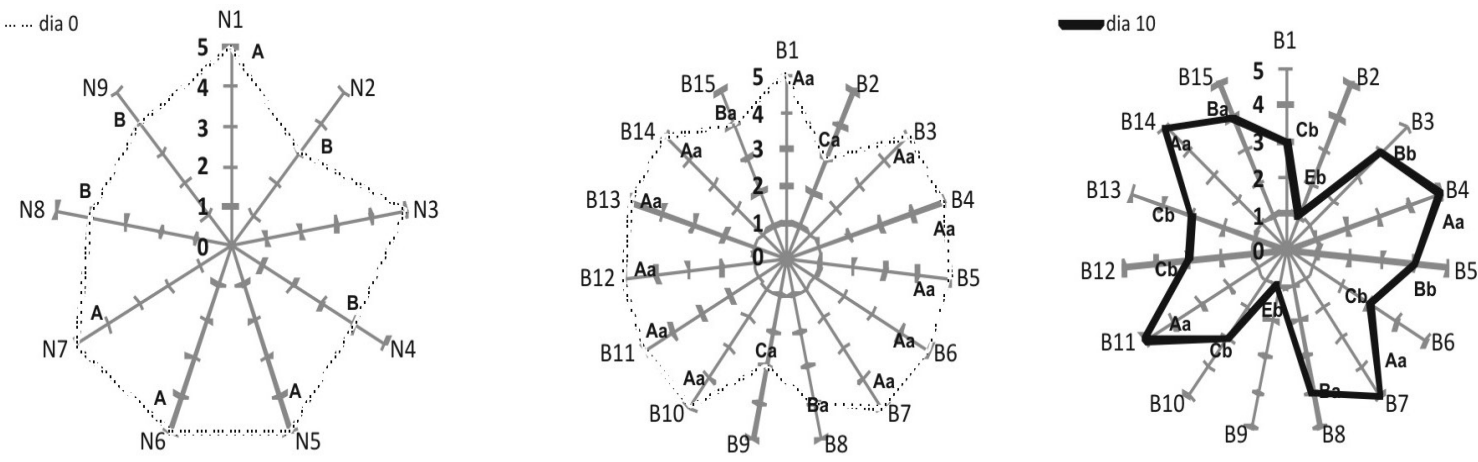

FIGURA 1- Teste de preferência (escala hedônica: 1-desgostei muitíssimo a 5-gostei muitíssimo) em néctares e blends de frutos tropicais e Amazônicos, no início do experimento (dia 0) e após armazenamento por 10 dias sem refrigeração, sob a adição de benzoato de sódio e dióxido de enxofre. Boa Vista-RR .

As médias seguidas das mesmas letras, maiúsculas (tratamentos) e minúsculas (tempo), não diferem entre si, ao nível de 5\% de probabilidade, pelo teste de Tukey.

Tratamentos: N1 - abacaxi; N2 - buriti; N3 - caju $\mathbf{N 4}$ - camu-camu; N5 - carambola; N6 - lima-ácida Tahiti; N7 - maracujá; N8 murici; N9 - taperebá; B1 - maracujá + abacaxi; B2 - abacaxi + buriti; B3 - abacaxi + caju; B4 - abacaxi + camu-camu; B5 - abacaxi + carambola; B6 - abacaxi + lima-ácida Tahiti; B7 - abacaxi + murici; B8 - abacaxi + taperebá; B9 - maracujá + buriti; B10 - maracujá + caju; B11 - maracujá + camu-camu; B12 - maracujá + carambola; B13 - maracujá + lima-ácida Tahiti; B14 - maracujá + murici; B15 - maracujá + taperebá. 
TABELA 4 - Composição nutricional média (em g.100 mL $\mathrm{mL}^{-1}$ ) dos néctares e blends de frutos tropicais e Amazônicos, no início do experimento (dia 0 ), sob a adição de benzoato de sódio e dióxido de enxofre. Boa Vista-RR.

\begin{tabular}{|c|c|c|c|c|c|c|c|c|c|}
\hline \multicolumn{3}{|c|}{ Proporções/Grupos } & \multicolumn{7}{|c|}{ Composição Nutricional } \\
\hline & & & Niacina & Cálcio & Fósforo & Ferro & Vit. B1 & Vit. B2 & Vit. C \\
\hline \multicolumn{2}{|c|}{$100 \%$} & abacaxi & $0,23 \mathrm{Ca}$ & $17,50 \mathrm{Ba}$ & $8,20 \mathrm{Ca}$ & $0,53 \mathrm{Ca}$ & $0,06 \mathrm{Aa}$ & $0,03 \mathrm{Ba}$ & $32,50 \mathrm{Ba}$ \\
\hline \multicolumn{2}{|c|}{$100 \%$} & maracujá & $1,60 \mathrm{Aa}$ & $12,45 \mathrm{Ba}$ & $17,20 \mathrm{Ba}$ & $1,85 \mathrm{Ba}$ & $0,03 \mathrm{Aa}$ & $0,15 \mathrm{Aa}$ & $33,15 \mathrm{Ba}$ \\
\hline \multirow[t]{4}{*}{ blends } & $1: 1$ & maracujá + abacaxi & $0,86 \mathrm{Ba}$ & $15,13 \mathrm{Ba}$ & $10,10 \mathrm{Ca}$ & $0,81 \mathrm{Ca}$ & $0,05 \mathrm{Aa}$ & $0,09 \mathrm{Ba}$ & $32,62 \mathrm{Ba}$ \\
\hline & $1: 1$ & abacaxi + buriti & $0,11 \mathrm{Ca}$ & $88,90 \mathrm{Aa}$ & $25,98 \mathrm{~A}$ & $2,19 \mathrm{Aa}$ & $0,04 \mathrm{Aa}$ & $0,17 \mathrm{Aa}$ & $25,50 \mathrm{Ba}$ \\
\hline & $1: 1$ & abacaxi + & $0,28 \mathrm{Ca}$ & $6,50 \mathrm{Ca}$ & $15,32 \mathrm{BCa}$ & $0,99 \mathrm{Ca}$ & $0,04 \mathrm{Aa}$ & $0,03 \mathrm{Ba}$ & $110,8 \mathrm{Ba}$ \\
\hline & 1:1 & abacaxi + camu-camu & $0,09 \mathrm{Ca}$ & $22,45 \mathrm{Ba}$ & $11,20 \mathrm{Ca}$ & $0,66 \mathrm{Ca}$ & $0,03 \mathrm{Aa}$ & $0,03 \mathrm{Ba}$ & $1120,3 \mathrm{Aa}$ \\
\hline \multirow[t]{7}{*}{ GI } & 1:1 & abacaxi + carambola & $0,19 \mathrm{Ca}$ & $28,62 \mathrm{Ba}$ & $9,72 \mathrm{Ca}$ & $2,10 \mathrm{Aa}$ & $0,06 \mathrm{Aa}$ & $0,03 \mathrm{Ba}$ & $29,14 \mathrm{Ba}$ \\
\hline & $1: 1$ & abac. + lima-ácida Tahiti & $0,21 \mathrm{Ca}$ & $25,25 \mathrm{Ba}$ & $12,55 \mathrm{Ca}$ & $0,62 \mathrm{Ca}$ & $0,03 \mathrm{Aa}$ & $0,03 \mathrm{Ba}$ & $31,20 \mathrm{Ba}$ \\
\hline & 1:1 & abacaxi + murici & $0,41 \mathrm{BCa}$ & $64,08 \mathrm{Aa}$ & $17,33 \mathrm{Ba}$ & $1,05 \mathrm{Ca}$ & $0,03 \mathrm{Aa}$ & $0,05 \mathrm{Ba}$ & $31,12 \mathrm{Ba}$ \\
\hline & $1: 1$ & abacaxi + taperebá & $0,33 \mathrm{Ca}$ & $22,29 \mathrm{Ba}$ & $19,01 \mathrm{Ba}$ & $1,86 \mathrm{Ba}$ & $0,06 \mathrm{Aa}$ & $0,05 \mathrm{Ba}$ & $27,44 \mathrm{Ba}$ \\
\hline & 1:1 & maracujá + buriti & $1,10 \mathrm{Aa}$ & $78,32 \mathrm{Aa}$ & $29,55 \mathrm{Aa}$ & $3,32 \mathrm{Aa}$ & $0,04 \mathrm{Aa}$ & $0,20 \mathrm{Aa}$ & $23,56 \mathrm{Ba}$ \\
\hline & 1:1 & maracujá + caju & $1,22 \mathrm{Aa}$ & $7,43 \mathrm{Ca}$ & $18,89 \mathrm{Ba}$ & $1,30 \mathrm{Ba}$ & $0,03 \mathrm{Aa}$ & $0,05 \mathrm{Ba}$ & $125,4 \mathrm{Ba}$ \\
\hline & 1:1 & maracujá + camu-camu & $1,05 \mathrm{Aa}$ & $19,94 \mathrm{Ba}$ & $16,01 \mathrm{BCa}$ & $0,86 \mathrm{Ca}$ & $0,03 \mathrm{Aa}$ & $0,07 \mathrm{Ba}$ & $1980,3 \mathrm{Aa}$ \\
\hline \multirow[t]{4}{*}{ GII } & $1: 1$ & maracujá + carambola & $1,03 \mathrm{Aa}$ & $23,64 \mathrm{Ba}$ & $14,96 \mathrm{BCa}$ & $2,29 \mathrm{Aa}$ & $0,04 \mathrm{Aa}$ & $0,04 \mathrm{Ba}$ & $30,12 \mathrm{Ba}$ \\
\hline & $1: 1$ & marac. + lima-ácida Tahiti & $1,20 \mathrm{Aa}$ & $24,30 \mathrm{Ba}$ & $17,43 \mathrm{Ba}$ & $1,12 \mathrm{BCa}$ & $0,03 \mathrm{Aa}$ & $0,05 \mathrm{Ba}$ & $33,31 \mathrm{Ba}$ \\
\hline & $1: 1$ & maracujá + murici & $1,32 \mathrm{Aa}$ & $55,70 \mathrm{Aa}$ & $19,67 \mathrm{Ba}$ & $1,65 \mathrm{Ba}$ & $0,03 \mathrm{Aa}$ & $0,08 \mathrm{Ba}$ & $34,20 \mathrm{Ba}$ \\
\hline & $1: 1$ & maracujá + taperebá & $1,28 \mathrm{Aa}$ & $20,20 \mathrm{Ba}$ & $23,50 \mathrm{Aa}$ & 2,39Aa & $0,06 \mathrm{Aa}$ & $0,11 \mathrm{BBa}$ & $29,23 \mathrm{Ba}$ \\
\hline
\end{tabular}

As médias seguidas das mesmas letras, nas colunas (tratamentos - maiúscula) e nas linhas* (tempo - minúscula), não diferem entre si ao nível de $5 \%$ de probabilidade, pelo teste de Tukey.

* Observar Tabela 5 para comparação das médias.

TABELA 5 - Comparação das perdas (em \%) da composição nutricional média (em g.100 mL $\left.\mathrm{m}^{-1}\right)$ dos néctares e blends de frutos tropicais e Amazônicos, no início do experimento (dia 0) e após armazenamento por 10 dias sem refrigeração, sob a adição de benzoato de sódio e dióxido de enxofre. Boa Vista-RR.

\begin{tabular}{|c|c|c|c|c|c|c|c|c|c|}
\hline \multirow{2}{*}{\multicolumn{3}{|c|}{ Proporções/Grupos }} & \multicolumn{7}{|c|}{ Composição Nutricional } \\
\hline & & & Niacina & Cálcio & Fósforo & Ferro & Vit. B1 & Vit. B2 & Vit. C \\
\hline \multicolumn{2}{|c|}{$100 \%$} & abacaxi & $-12,23 \mathrm{~B}$ & $-(1)$ & - & - & $-18,19 \mathrm{~B}$ & $-13,76 \mathrm{~B}$ & $-72,5 \mathrm{AB}$ \\
\hline \multicolumn{2}{|c|}{$100 \%$} & maracujá & $-10,15 \mathrm{~B}$ & - & - & - & $-19,98 \mathrm{~B}$ & $-14,54 \mathrm{~B}$ & $-68,9 \mathrm{~B}$ \\
\hline \multirow[t]{4}{*}{ blends } & $1: 1$ & maracujá + abacaxi & $-8,14 \mathrm{~B}$ & - & - & - & $-10,45 \mathrm{C}$ & $-12,54 \mathrm{~B}$ & $-65,0 \mathrm{~B}$ \\
\hline & $1: 1$ & abacaxi + buriti & $-33,12 \mathrm{~A}$ & - & - & - & $-28,47 \mathrm{~A}$ & $-35,76 \mathrm{~A}$ & $-82,4 \mathrm{~A}$ \\
\hline & $1: 1$ & abacaxi + caju & $-8,24 \mathrm{~B}$ & - & - & - & $-9,33 \mathrm{C}$ & $-8,67 \mathrm{~B}$ & $-61,3 \mathrm{~B}$ \\
\hline & $1: 1$ & abacaxi + camu-camu & $-6,98 \mathrm{~B}$ & - & - & - & $-9,08 \mathrm{C}$ & $-4,88 \mathrm{C}$ & $-41,9 \mathrm{C}$ \\
\hline \multirow[t]{7}{*}{ GI } & $1: 1$ & abacaxi + carambola & $-9,80 \mathrm{~B}$ & - & - & - & $-12,65 \mathrm{C}$ & $-10,98 \mathrm{~B}$ & $-66,4 \mathrm{~B}$ \\
\hline & $1: 1$ & bacaxi + lima-ácida Tahiti & $-10,35 \mathrm{~B}$ & - & - & - & $-9,80 \mathrm{C}$ & $-9,54 \mathrm{~B}$ & $-63,2 \mathrm{~B}$ \\
\hline & $1: 1$ & abacaxi + murici & $-11,20 \mathrm{~B}$ & - & - & - & $-10,98 \mathrm{C}$ & $-12,33 \mathrm{~B}$ & $-67,2 \mathrm{~B}$ \\
\hline & $1: 1$ & abacaxi + taperebá & $-12,67 \mathrm{~B}$ & - & - & - & $-13,34 \mathrm{C}$ & $-12,90 \mathrm{~B}$ & $-68,2 \mathrm{~B}$ \\
\hline & $1: 1$ & maracujá + buriti & $-29,30 \mathrm{~A}$ & - & - & - & $-30,12 \mathrm{~A}$ & $-34,90 \mathrm{~A}$ & $-77,2 \mathrm{~A}$ \\
\hline & $1: 1$ & maracujá + caju & $-7,38 \mathrm{~B}$ & - & - & - & $-8,89 \mathrm{C}$ & $-9,40 \mathrm{~B}$ & $-55,5 \mathrm{~B}$ \\
\hline & $1: 1$ & marac. + camu-camu & $-4,89 \mathrm{~B}$ & - & - & - & $-6.90 \mathrm{C}$ & $-4,12 \mathrm{C}$ & $-43,3 \mathrm{C}$ \\
\hline \multirow[t]{4}{*}{ GII } & $1: 1$ & maracujá + carambola & $-8,87 \mathrm{~B}$ & - & - & - & $-9,92 \mathrm{C}$ & $-9,12 \mathrm{~B}$ & $-59,3 \mathrm{~B}$ \\
\hline & 1:1 & marac. + lima-ácida Tahiti & $-9,45 B$ & - & - & - & $-10,10 \mathrm{C}$ & $-9,76 \mathrm{~B}$ & $-58,6 \mathrm{~B}$ \\
\hline & $1: 1$ & maracujá + murici & $-9,23 \mathrm{~B}$ & - & - & - & $-8,76 \mathrm{C}$ & $-10,06 \mathrm{~B}$ & $-69,1 \mathrm{~B}$ \\
\hline & $1: 1$ & maracujá + taperebá & $-10,07 \mathrm{~B}$ & - & - & - & $-10,35 \mathrm{C}$ & $-11,23 \mathrm{~B}$ & $-66,8 \mathrm{~B}$ \\
\hline
\end{tabular}

(1) Perdas não detectadas.

As médias seguidas das mesmas letras, nas colunas (tratamentos), não diferem entre si, ao nível de 5\% de probabilidade, pelo teste de Tukey. 
TABELA 6 - Composição nutricional média (em g. $100 \mathrm{~mL}^{-1}$ ) dos néctares e blends de frutos tropicais e Amazônicos, armazenados por 10 dias sem refrigeração, sob a adição de benzoato de sódio e dióxido de enxofre. Boa Vista-RR.

\begin{tabular}{|c|c|c|c|c|c|c|c|c|}
\hline \multicolumn{3}{|c|}{ Proporções/Grupos } & \multicolumn{6}{|c|}{ Composição Nutricional } \\
\hline & & & Niacina & Cálcio & Fósforo & Ferro & Vit. B1 Vit. B2 & Vit. C \\
\hline \multicolumn{2}{|c|}{$100 \%$} & abacaxi & $0,20 \mathrm{Cb}$ & $17,50 \mathrm{Ba}$ & $8,20 \mathrm{Ca}$ & $0,53 \mathrm{Ca}$ & $0,05 \mathrm{Aa} 0,02 \mathrm{Aa}$ & $8,94 \mathrm{Bb}$ \\
\hline \multicolumn{2}{|c|}{$100 \%$} & maracujá & $1,43 \mathrm{Ab}$ & $12,45 \mathrm{Ba}$ & $17,20 \mathrm{Ba}$ & $1,85 \mathrm{Ba}$ & $0,02 \mathrm{Aa} 0,12 \mathrm{Aa}$ & $10,31 \mathrm{Bb}$ \\
\hline blends & $1: 1$ & maracujá + abacaxi & $0,21 \mathrm{Cb}$ & $15,13 \mathrm{Ba}$ & $10,10 \mathrm{Ca}$ & $0,81 \mathrm{Ca}$ & $0,04 \mathrm{Aa} 0,08 \mathrm{Aa}$ & $11,41 \mathrm{Bb}$ \\
\hline \multirow{7}{*}{ GI } & $1: 1$ & abacaxi + buriti & $0,07 \mathrm{Db}$ & $88,90 \mathrm{Aa}$ & $25,98 \mathrm{Aa}$ & $2,19 \mathrm{Aa}$ & $0,02 \mathrm{Aa} 0,11 \mathrm{Aa}$ & $4,49 \mathrm{Bb}$ \\
\hline & 1:1 & abacaxi + caju & $0,26 \mathrm{Cb}$ & $6,50 \mathrm{Ca}$ & $15,32 \mathrm{BCa}$ & $0,99 \mathrm{Ca}$ & $0,03 \mathrm{Aa} 0,02 \mathrm{Aa}$ & $45,88 \mathrm{Bb}$ \\
\hline & $1: 1$ & abac. + camu-camu & $0,08 \mathrm{Da}$ & $22,45 \mathrm{Ba}$ & $11,20 \mathrm{Ca}$ & $0,66 \mathrm{Ca}$ & $0,02 \mathrm{Aa} 0,02 \mathrm{Aa}$ & $650,88 \mathrm{Ab}$ \\
\hline & 1:1 & abacaxi + carambola & $0,17 \mathrm{Cb}$ & $28,62 \mathrm{Ba}$ & $9,72 \mathrm{Ca}$ & $2,10 \mathrm{Aa}$ & $0,05 \mathrm{Aa} 0,02 \mathrm{Aa}$ & $9,80 \mathrm{Bb}$ \\
\hline & $1: 1$ & abac. + lima-ácida $\mathrm{T}$. & $0,18 \mathrm{Cb}$ & $25,25 \mathrm{Ba}$ & $12,55 \mathrm{Ca}$ & $0,62 \mathrm{Ca}$ & $0,02 \mathrm{Aa} 0,02 \mathrm{Aa}$ & $11,49 \mathrm{Bb}$ \\
\hline & $1: 1$ & abacaxi + murici & & $64,08 \mathrm{Aa}$ & & $1,05 \mathrm{Ca}$ & $0,02 \mathrm{Aa} 0,04 \mathrm{Aa}$ & $10,17 \mathrm{Bb}$ \\
\hline & $1: 1$ & abacaxi + taperebá & $0,28 \mathrm{Cb}$ & $22,29 \mathrm{Ba}$ & $19,01 \mathrm{Ba}$ & $1,86 \mathrm{Ba}$ & $0,05 \mathrm{Aa} 0,04 \mathrm{Aa}$ & $8,73 \mathrm{Bb}$ \\
\hline \multirow{7}{*}{ GII } & $1: 1$ & maracujá + buriti & $0,77 \mathrm{BCb}$ & $78,32 \mathrm{Aa}$ & $29,55 \mathrm{Aa}$ & $3,32 \mathrm{Aa}$ & $0,02 \mathrm{Aa} 0,01 \mathrm{Aa}$ & $5,38 \mathrm{Bb}$ \\
\hline & $1: 1$ & maracujá + caju & $1,13 \mathrm{Ab}$ & $7,43 \mathrm{Ca}$ & $18,89 \mathrm{Ba}$ & $1,30 \mathrm{Ba}$ & $0,02 \mathrm{Aa} 0,04 \mathrm{Aa}$ & $55,80 \mathrm{Bb}$ \\
\hline & $1: 1$ & marac. + camu-camu & $0,99 \mathrm{Ba}$ & $19,94 \mathrm{Ba}$ & $16,01 \mathrm{BCa}$ & $0,86 \mathrm{Ca}$ & $0,02 \mathrm{Aa} 0,06 \mathrm{Aa}$ & $1122,2 \mathrm{Ab}$ \\
\hline & $1: 1$ & marac. + carambola & $0,94 \mathrm{Bb}$ & $23,64 \mathrm{Ba}$ & $14,96 \mathrm{BCa}$ & $2,29 \mathrm{Aa}$ & $0,03 \mathrm{Aa} 0,03 \mathrm{Aa}$ & $12,25 \mathrm{Bb}$ \\
\hline & $1: 1$ & marac. + lima-ácida $T$. & $1,08 \mathrm{Ab}$ & $24,30 \mathrm{Ba}$ & $17,43 \mathrm{Ba}$ & $1,12 \mathrm{BCa}$ & $0,02 \mathrm{Aa} 0,04 \mathrm{Aa}$ & $13,80 \mathrm{Bb}$ \\
\hline & $1: 1$ & maracujá + murici & $1,11 \mathrm{Ab}$ & $55,70 \mathrm{Aa}$ & $19,67 \mathrm{Ba}$ & $1,65 \mathrm{Ba}$ & $0,02 \mathrm{Aa} 0,07 \mathrm{Aa}$ & $10,57 \mathrm{Bb}$ \\
\hline & $1: 1$ & maracujá + taperebá & $1,15 \mathrm{Ab}$ & $20,20 \mathrm{Ba}$ & $23,50 \mathrm{Aa}$ & $2,39 \mathrm{Aa}$ & $0,05 \mathrm{Aa} 0,09 \mathrm{Aa}$ & $9,70 \mathrm{Bb}$ \\
\hline
\end{tabular}

As médias seguidas das mesmas letras, nas colunas (tratamentos - maiúscula) e nas linhas* (tempo - minúscula), não diferem entre si, ao nível de $5 \%$ de probabilidade, pelo teste de Tukey.

* Observar Tabela 4 para comparação das médias.

\section{CONCLUSÃO}

Diante dos resultados apresentados, constatou-se:

1 - À exceção das combinações com o buriti, devido ao comprometimento microbiológico, os demais blends apresentam incrementos satisfatórios na composição nutricional e sensorial.

2 - Os blends que contém o camu-camu e o murici como componentes, mesmo após 10 dias de conservação sem o uso da refrigeração, são considerados os melhores mixes no painel sensorial.

\section{REFERÊNCIAS}

AMERICAN PUBLIC HEALTH ASSOCIATION. Compendium of methods for the microbiological examination of foods. $4^{\text {th }}$ ed. Washington DC: American Public Health Association, 2001. 676p.

AOAC - Association OfOfficial Analytical Chemists. Official methods of analysis of aoac international. 17. ed. Gaithersburg, 2000.

ANVISA - Agência Nacional de Vigilância Sanitária. Resolução RCD n. 12, de 2 de janeiro de 2001. Disponível em: $<$ http://www.anvisa.gov.br $>$. Acesso em: 23 jul. 2009.

BONNAS, S.D.; CHITARRA, A.B.; PRADO, M.E.T.; JÚNIOR, D.T. Qualidade do abacaxi cv. Smooth Cayenne minimamente processado. Revista Brasileira de Fruticultura, Jaboticabal, n.2, v. 25, p. 206-209, 2003. 
BONOMO, R. C. F.; CARNEIRO, J. C. de S.; BATISTA, S. A.; PIRAJÁ, D. C. R.; FONTAN, R. da C. I.; CARVALHO, B. M. A. de; COSTA, A. M. G.; SILVA, A. A. L. da. Desenvolvimento e avaliação sensorial de um "mix" de polpa congelada à base de cajá (Spondias mombim L.) e graviola (Annona muricata L.). Revista Brasileira de Produtos Agroindustriais, Campina Grande, n.1, v.8, p.11-15, 2006.

BRANCO, I.G.; SANJINEZ-ARGANDOÑA, E.J.; SILVA, M.M.; PAULA,T.M. Avaliação sensorial estabilidade físico-química de um blend e laranja e cenoura. Ciência e Tecnologia de Alimentos, Campinas, n. 1, v.27, p.787-792, 2007.

BRASIL. Ministério da Agricultura, Pecuária e Abastecimento. Instrução normativa n. ${ }^{\circ} 12$, de 4 de setembro de 2003. Aprovar o regulamento técnico para a fixação de padrões de identidade e qualidade gerais de sucos tropicais e néctares e outros. Diário Oficial da União, Brasília-DF, 9 set. 2003. Seção 1, p.2.

CARVALHO, C. R. L.; MANTOVANI, D. M. B.; CARVALHO, P. R. N.; MORAES, R. M. M. Análises químicas de alimentos: manual técnico. Campinas: Instituto de Tecnologia de Alimentos, 1990. 121p.

COSTA, M. C.; MAIA, G. A.; SOUZA FILHO, M. de S.M. MEN.; FIGUEIREDO, R. W. de; NASSU, R. T.; MONTEIRO, J. C. S. Conservação de polpa de cupuaçu [Theobroma grandiflorum (Willd. Ex Spreng.) Schum] por métodos combinados. Revista Brasileira de Fruticultura, Jaboticabal, n.2, v.25, p. 115-118, 2003.

FARIAS, J. P. de; B.G.; LIMA, E. D. P. de A. Obtenção de néctar de abacaxi (Ananas comosus L.) com adição de infusões de chá verde (Camellia sinensis), gengibre (Zingiber officinale) e hortelã (Plectranthus amboinicus L.). In: FÓRUM CIENTÍFICO DE DEBATES DA FACULDADE DE CIÊNCIAS MÉDICAS DA PARAÍBA, 6., 2008. João Pessoa, Anais... p. 136.

FOLEGATTI, M. I. S.; FERREIRA, D.C.; MATSUURA, F. C. A. U. Otimização da aceitação de néctar de mamão e acerola através de metodologia de superfície de resposta. In: Congresso Brasileiro de Ciência e Tecnologia de Alimentos, 17., Fortaleza, 2000. Anais... Campinas: SBCTA, v.1, p.319, 2000.
LAM, F. L.; HOLCOMB, I. J.; FUSARI, S. A. Liquid chromatographic assay of ascorbic acid, nicotinamide, pyridoxine, thiamine and riboflavin in multivitamin-mineral preparations. Journal of Association off Analytical Chemistry, Washington, n.5, v.67, p. 1007-1011, 1984.

MATSUURA, F. C. A. U.; FOLEGATTI, M. I. da S.; CARDOSO, R. L.; FERREIRA, D. C. Sensory acceptance of mixed nectar of papaya, passion fruit and acerola. Scientia Agrícola, Piracicaba, n.6, v.61, p. 604-608, 2004.

MATSUURA, F. C. A. U.; ROLIM, R. B. Avaliação da adição de suco de acerola em suco de abacaxi visando à produção de um "blend" com alto teor de vitamina C. Revista Brasileira de Fruticultura, Jaboticabal, n.1, v.24, 2002.

MATTIUZ, B. H.; MIGUEL, A. C. A.; NACHTIGAL, J. C.; DURIGAN, J. F.; CAMARGO, U. A. Processamento mínimo de uvas de mesa sem semente. Revista Brasileira de Fruticultura, Jaboticabal, v.26, n.2, p.226-229, 2004

MORAES, M.A.C. Métodos para avaliação sensorial dos alimentos. 6.ed. Campinas: Editora Unicamp, 1988.

MOSTAFA, G. A.; ABD EL-HADY, E. A.; ASKAR, A. Preparation of papaya and mango nectar blends. Fruit Processing, Chicago, v.5, p.180-185, 1997.

NEVES, L.C.; BENEDETTE, R. M.; SILVA, V. X. da; PRILL, M. A. de S. Pós-Colheita de Fruteiras Tropicais In: NEVES, L. C. Manual pós-colheita da fruticultura brasileira. Londrina: EDUEL, 2009. p.412-418.

NEVES, L.C.; PRILL, M.A. de S.; SILVA, V.X. da; BENEDETTE, R.L.;VIEITES, R.L. Avaliação de diferentes tipos de atmosferas modificadas na vida útil de carambolas minimamente processadas. Revista Brasileira de Fruticultura, Jaboticabal, v.28, n.3, p.467-472, 2006.

QUINTEROS, E. T. T. Processamento e estabilidade de néctares de acerola-cenoura. $1995.96 \mathrm{f}$. Dissertação (Mestrado em Tecnologia de Alimentos) - Faculdade de Engenharia de Alimentos, Universidade Estadual de Campinas, Campinas, 1995. 
SILVA, T. V.; RESENDE, E. D. de; VIANA, A. P.; ROSA, R. C. C.; PEREIRA, S. M. de F.; CARLOS, L. de A.; VITORAZI, L. Influência dos estádios de maturação na qualidade do suco do maracujá-amarelo. Revista Brasileira de Fruticultura, Jaboticabal, n.3, v.27, p. 472-475, 2005.

SOARES, L. C.; OLIVEIRA, G. S. F.; MAIA, G. A.; MONTEIRO, J. C. S.; SILVA JUNIOR, A. Obtenção de bebida a partir de suco de caju (Anacardium occidentale L.) e extrato de guaraná (Paullinia cupana sorbilis Mart. Ducke). Revista Brasileira de Fruticultura, Jaboticabal, n.2, v.23, p.387-390, 2001.
TIWARI, R.B. Studies on blending of guava and papaya pulp for RTS beverage. Indian Food Packer, New Delhi, v.54, p.68-72, 2000.

VAN DE WEERDHOF, T.; WIERSUN, M.L.; REISSENWEBER, H. Application of liquid cromatography in food analysis. Journal of Chromatography, Amsterdam, v. 83, p. 455-460, 1973. 